\title{
Optimal Siting of Distributed Generators in a Distribution Network using Artificial Immune System
}

\author{
Meera P.S., S. Hemamalini \\ School of Electrical Engineering, VIT University, Chennai, India
}

\begin{tabular}{l}
\hline \hline Article Info \\
\hline Article history: \\
Received Oct 11, 2016 \\
Revised Dec 28, 2016 \\
Accepted Jan 12, 2017 \\
\hline
\end{tabular}

\section{Keyword:}

Artificial immune system

Distributed generation

Multi-objective

Optimal power flow

Optimal siting

\begin{abstract}
Distributed generation (DG) sources are being installed in distribution networks worldwide due to their numerous advantages over the conventional sources which include operational and economical benefits. Random placement of DG sources in a distribution network will result in adverse effects such as increased power loss, loss of voltage stability and reliability, increase in operational costs, power quality issues etc. This paper presents a methodology to obtain the optimal location for the placement of multiple DG sources in a distribution network from a technical perspective. Optimal location is obtained by evaluating a global multi-objective technical index (MOTI) using a weighted sum method. Clonal selection based artificial immune system (AIS) is used along with optimal power flow (OPF) technique to obtain the solution. The proposed method is executed on a standard IEEE-33 bus radial distribution system. The results justify the choice of AIS and the use of MOTI in optimal siting of DG sources which improves the distribution system efficiency to a great extent in terms of reduced real and reactive power losses, improved voltage profile and voltage stability. Solutions obtained using AIS are compared with Genetic algorithm (GA) and Particle Swarm optimization (PSO) solutions for the same objective function.
\end{abstract}

Copyright $@ 2017$ Institute of Advanced Engineering and Science. All rights reserved.

\section{Corresponding Author:}

Meera P.S.,

School of Electrical Engineering,

VIT University, Chennai, India.

meera.ps@vit.ac.in

\section{INTRODUCTION}

Deregulation of the electric power industry and concern over the greenhouse gas emissions are the main reasons behind the renewed interest in distributed generation. DG sources are usually smaller than 100 MW and will be connected to the distribution systems, typically of voltage range $230 / 400 \mathrm{~V}$ up to $145 \mathrm{kV}$ [1]. Distributed generation sources may be either renewable or non-renewable in nature. Micro turbines, wind, photovoltaic, small hydro, fuel cells, gas turbines etc are some of the commonly used DG sources [2]. With the integration of DG sources, the traditionally passive distribution network becomes an active one. This leads to bidirectional power flow which introduces several operational constraints. Recent smart grid initiatives also promote the increased integration of distributed energy resources into the network. During faults, islanding operation can result in the formation of micro grids thereby reducing grid disturbances and strengthening the grid stability [3].

The impact of DG sources on distribution network changes with the level of penetration as well as its location. Finding the optimal location is important because placement of DG sources at certain nodes may result in over voltages, increased losses and an increase in fault level affecting the distribution system safety and reliability [4]. Many papers are available in the literature addressing the issue of optimal siting and sizing of distributed generators. Analytical [5], numerical [6] and heuristic methods [7] have been used to solve this complex, nonlinear problem with nonlinear constraints [8]. Many researchers have found out the optimal 
location of distributed generators with objectives like minimum power loss [9], [10], minimum cost [11], maximum DG penetration [12], maximum reliability [13] and maximum voltage stability index [14]. A multi-objective performance index [15] for distribution networks with time varying distributed generation is proposed. The objectives considered are losses, voltage profile, reserve capacity of conductors and short circuit levels. A Kalman filter based algorithm [16] to select the optimal location and size of multiple DGs considering total power loss is developed. The proposed method reduced the computational efforts of the optimization process significantly. Simultaneous DG and capacitor placement is done by means of a multi objective function consisting of loss reduction, voltage improvement and available transfer capacity using genetic algorithm in [17]. Evolutionary particle swarm optimization (EPSO) is used [18] to optimize the DG capacity considering power loss and voltage profile improvement.

A multi-objective harmony search algorithm [19] to evaluate the impact of DG placement for optimal planning is presented. The objective functions considered are power loss and voltage profile improvement. A multi-objective particle swarm optimization [20] is proposed to determine the optimal DG location, size, and generated power contract price. The objective of this optimization is to minimize the distribution company's cost and maximize the DG owner's benefit simultaneously. The optimal placement problem is formulated as a mixed integer programming [21] considering the probabilistic nature of DG outputs and load consumption, wherein the costs are minimized and profits are maximized. From the literature carried out it is clear that artificial immune system (AIS) is not used widely to solve this optimization problem.

In this paper, the feasibility of AIS technique for the DG optimal placement problem is evaluated and its performance is compared with that Genetic algorithm (GA) and Particle Swarm Optimization (PSO) algorithm results. The problem is solved using a multi-objective index considering real and reactive power losses, voltage stability and voltage regulation. The problem is solved using clonal selection based AIS algorithm along with optimal power flow. The DG sources usually have a predetermined capacity and it is impractical to alter its output according to the variations in the load throughout a day. Hence in this paper the DG sizes are chosen from a given set of discrete DG sizes and peak load level is considered throughout the analysis. The optimal siting problem is solved for installing three DG sources in the distribution network. The algorithm is tested on an IEEE 33 bus system.

\section{MULTI-OBJECTIVE TECHNICAL INDEX FORMULATION}

The multi-objective technical index elucidates the different impacts of integration of DG sources from a technical perspective. MOTI is formulated with four different objective functions and it is solved as a maximization problem using weighted sum method. The four objectives are to minimize the real and reactive power loss, improve the voltage regulation and voltage stability. The location of DG which gives the minimum real power loss may not be the one with the best voltage profile. Hence it is important to consider all these objectives simultaneously. The various indices used for MOTI are explained below.

\subsection{Real Power Loss Index (RPLI)}

The real power loss is obtained from load flow analysis. The node which gives the minimum active power loss is preferred for DG placement. The value of RPLI ${ }^{\mathrm{k}}$ for the $\mathrm{k}^{\text {th }}$ distribution network configuration is obtained from (1), where $\mathrm{P}_{\text {Loss }_{i}}$ is the real power loss for each section of the distribution network and it is evaluated using (2).

$$
\begin{aligned}
\mathrm{RPLI}^{\mathrm{k}} & =1-\left[\frac{\sum \mathrm{P}_{\text {Loss }_{\mathrm{i}, \mathrm{with} \mathrm{DG}}}{ }^{k}}{\sum \mathrm{P}_{\text {Loss }_{\mathrm{i}, \text { no DG }}}}\right] \\
\mathrm{P}_{\text {Loss }_{\mathrm{i}}} & =\left[\frac{\mathrm{P}_{\mathrm{i}}{ }^{2}+\mathrm{Q}_{\mathrm{i}}{ }^{2}}{\mathrm{~V}_{\mathrm{i}}{ }^{2}}\right] \mathrm{r}_{\mathrm{i}+1}
\end{aligned}
$$

where $P_{\text {Loss }}$ is the real power loss between buses $\mathrm{i}$ and $\mathrm{i}+1, \mathrm{P}_{\mathrm{i}}$ and $\mathrm{Q}_{\mathrm{i}}$ are the real and reactive power flow from bus $i$ to bus $i+1, r_{i+1}$ is the resistance of the line connecting bus $i$ and bus $i+1$.

\subsection{Reactive Power Loss Index (QPLI)}

The value of QPLI is calculated using (3) and the reactive power loss for each section in a distribution network, $Q_{\text {Loss }}$ is given by (4).

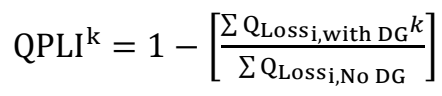




$$
\mathrm{Q}_{\mathrm{Loss}_{\mathrm{i}+1}}=\left[\frac{\mathrm{P}_{\mathrm{i}}{ }^{2}+\mathrm{Q}_{\mathrm{i}}{ }^{2}}{\mathrm{~V}_{\mathrm{i}}{ }^{2}}\right] \mathrm{X}_{\mathrm{i}+1}
$$

where $x_{i+1}$ is the reactance of the line connecting buses $i$ and $i+1$.

\subsection{Voltage Regulation Index (VRI)}

In a distribution network, when DG sources are installed, the network voltages tend to vary. In order to understand this effect, especially for a critical operating case like minimum demand and maximum generation, the voltage regulation index is calculated. The minimum load condition is considered as $10 \%$ of the peak load. For the best location, the voltage regulation value should be the least or the VRI value as calculated from (5) should be closer to unity.

$$
\mathrm{VRI}^{\mathrm{k}}=1-\max \left[\sum_{\mathrm{i}=1}^{\mathrm{n}} \frac{\left(\mathrm{v}_{\mathrm{i}}^{\min , k}-\mathrm{v}_{\mathrm{i}}^{\max , k}\right)}{\mathrm{v}_{\mathrm{i}}^{\min , k}}\right]
$$

where $V_{i}^{\min , k}$ is the voltage at node ' $i$ ' when the load is minimum and $V_{i}^{\max , k}$ is the voltage at node ' $i$ ' when the load is maximum, i.e. peak load for the $\mathrm{k}^{\text {th }}$ distribution network configuration.

\subsection{Voltage Stability Index (VSI)}

The voltage stability index is evaluated using (6). The node with the minimum value of VSI is prone to voltage collapse/instability under critical load conditions [22]. Such nodes are the best locations for DG placement.

$$
\mathrm{VSI}^{\mathrm{k}}=\min \left(\mathrm{V}_{\mathrm{i}}^{4}-4\left[\left(\mathrm{r}_{\mathrm{i}+1} \mathrm{P}_{\mathrm{i}}+\mathrm{x}_{\mathrm{i}+1} \mathrm{Q}_{\mathrm{i}}\right)^{2}+\left(\mathrm{x}_{\mathrm{i}+1} \mathrm{Q}_{\mathrm{i}}+\mathrm{r}_{\mathrm{i}+1} \mathrm{P}_{\mathrm{i}}\right) \mathrm{V}_{\mathrm{i}}^{2}\right]\right)
$$

where $\mathrm{V}_{\mathrm{i}}$ is the voltage at node ' $\mathrm{i}$ '.

The multi-objective technical index (MOTI) for the $\mathrm{k}^{\text {th }}$ distribution network configuration is formulated using weighted sum method as given in (7). The summation of the weights is taken as unity.

$$
\operatorname{MOTI}^{\mathrm{k}}=\mathrm{RPLI}^{\mathrm{k}} \mathrm{x} \mathrm{w}_{1}+\mathrm{QPLI}^{\mathrm{k}} \mathrm{x} \mathrm{w}_{2}+\mathrm{VRI}^{\mathrm{k}} \mathrm{x} \mathrm{w}_{3}+\mathrm{VSI}^{\mathrm{k}} \times \mathrm{w}_{4}
$$

To obtain the optimal location for the placement of DG sources, MOTI is to be maximized as given in (8).

$$
\text { Maximize } \quad\left\{\mathrm{RPLI}^{\mathrm{k}} \times \mathrm{w}_{1}+\mathrm{QPLI}^{\mathrm{k}} \mathrm{x} \mathrm{w}_{2}+\mathrm{VRI}^{\mathrm{k}} \times \mathrm{w}_{3}+\mathrm{VSI}^{\mathrm{k}} \mathrm{x} \mathrm{w}_{4}\right\}
$$

The multi-objective problem is solved taking into consideration the following constraints.

1) Power flow constraints [23]

$$
\begin{aligned}
& \mathrm{P}_{\mathrm{i}+1}=\mathrm{P}_{\mathrm{i}}-\frac{\mathrm{r}_{\mathrm{i}+1}\left(\mathrm{P}_{\mathrm{i}}{ }^{2}+\mathrm{Q}_{\mathrm{i}}{ }^{2}\right)}{\mathrm{V}_{\mathrm{i}}{ }^{2}}-\mathrm{P}_{\mathrm{L}_{\mathrm{i}+1}}+\mu_{\mathrm{P}} \mathrm{AP}_{\mathrm{i}+1} \\
& \mathrm{Q}_{\mathrm{i}+1}=\mathrm{Q}_{\mathrm{i}}-\frac{\mathrm{x}_{\mathrm{i}+1}\left(\mathrm{P}_{\mathrm{i}}{ }^{2}+\mathrm{Q}_{\mathrm{i}}{ }^{2}\right)}{\mathrm{V}_{\mathrm{i}}{ }^{2}}-\mathrm{Q}_{\mathrm{L}_{\mathrm{i}+1}}+\mu_{\mathrm{q}} \mathrm{AQ}_{\mathrm{i}+1} \\
& \mathrm{~V}_{\mathrm{i}+1}{ }^{2}=\mathrm{V}_{\mathrm{i}}{ }^{2}-2\left(\mathrm{r}_{\mathrm{i}+1} \mathrm{P}_{\mathrm{i}}+\mathrm{x}_{\mathrm{i}+1} \mathrm{Q}_{\mathrm{i}}\right)+\left(\mathrm{r}_{\mathrm{i}+1}{ }^{2}+\mathrm{x}_{\mathrm{i}+1}{ }^{2}\right) \times \frac{\left(\mathrm{P}_{\mathrm{i}}{ }^{2}+\mathrm{Q}_{\mathrm{i}}{ }^{2}\right)}{\mathrm{V}_{\mathrm{i}}{ }^{2}}
\end{aligned}
$$

where $\mathrm{AP}_{\mathrm{i}+1}$ is the active power injected at bus ' $\mathrm{i}+1$ ', $\mu_{\mathrm{p}}$ and $\mu_{\mathrm{q}}$ are the real and reactive power multipliers. The multipliers $\mu_{\mathrm{P}}$ and $\mu_{\mathrm{q}}$ are set to zero when there is no active and reactive power source respectively and set to one when there is a source.

2) Voltage constraint

$$
\mathrm{V}_{\min } \leq \mathrm{V}_{\mathrm{i}} \leq \mathrm{V}_{\max }
$$

where $V_{\min }$ and $V_{\max }$ are the minimum and maximum voltage limits in per unit.

3) DG capacity constraints

$$
\mathrm{P}_{\mathrm{DG}, \min } \leq \mathrm{P}_{\mathrm{DG}, \mathrm{i}} \leq \mathrm{P}_{\mathrm{DG}, \max }
$$


where $P_{D G \text {,min }}$ and $P_{D G \text {,max }}$ are the minimum and maximum allowable DG sizes. In this paper, the DG capacities are chosen from a preselected set where the DG sizes are discretized. This is based on the assumption that DG sources will be usually available at standard sizes and it will be operating at its full capacity.

\section{ARTIFICIAL IMMUNE SYSTEM}

Human body is having a unique defense system called the immune system which protects the body from different disease causing pathogens, germs and other toxic substances. These foreign particles which attack the body and stimulate the immune system are termed as antigens. Immune system consists of innate immune system and adaptive immune system. Innate immunity is a nonspecific defense mechanism and it encounters the antigens with the help of physical barriers such as skin, chemicals in the blood and immune cells. Adaptive immunity is more complex, antigen specific and also has immunological memory associated with it. After the primary immune response, the body will be ready to combat any further infection due to the immunological memory it has attained with the help of memory cells. Hence the secondary immune response will be faster and more specific. The adaptive or acquired immune system consists of lymphocytes, namely B cells and $\mathrm{T}$ cells. B cells respond to antigens by producing specific antibodies whereas $\mathrm{T}$ cells directly attack the cells that carry the specific antigens. When the antibody on the surface of the B cell binds an antigen, the $\mathrm{B}$ cell gets stimulated. The level of stimulation depends on the capability of the B cell to recognize a specific antigen and also its affinity with other B cells. Once the stimulation level crosses the limit, the B cell transforms to a blast cell and divides to form large number of clones. This is termed as clonal proliferation. To produce a diverse set of antibodies and thus make the immune system more adaptive, the clones undergo mutation at very high frequencies termed as somatic hyper mutation. The newly produced B cells due to clonal proliferation and somatic hyper mutation will survive depending upon their affinity to the specific antigens as well as with other B cells [24]. This adaptive nature of the immune system is emulated by the clonal selection based AIS algorithm [25].

\subsection{Clonal Selection Based AIS Algorithm}

In this algorithm, initially a random population of antibodies is generated. These are the candidate solutions for the optimization problem. Then affinity is calculated for each of these antibodies. A memory set is formed with these individuals. In maximization problem, the solutions having higher values of the objective function will have greater affinity. These antibodies undergo clonal proliferation proportional to their affinity. Thus more clones are generated for antibodies with higher fitness function values. Then hyper mutation is performed to these clones at a rate inversely proportional to affinity. The inferior antibodies undergo mutation with a higher mutation rate. Again affinity is evaluated for the mutated individuals. This completes the first iteration. The process is repeated until the stopping criterion is satisfied and each time the memory set has to be updated by replacing the inferior antibodies with the new improved individuals.

\subsection{Implementation of AIS Algorithm for Optimal Siting of DG Sources}

The steps involved in the AIS algorithm for optimal siting of DG sources in a distribution network are as follows.

1. Input the line and load data of the distribution network, the ratings of the DG sources and the voltage limits. Perform the load flow analysis for the test system without DG sources.

2. Generate a random population of individuals or antibodies. Real coding is used for representing the antibodies. The antibodies that violate the constraints are removed from the population. The antibodies give the locations for installing the DG sources and can be represented as $A b_{\mathrm{i}}=\left\{\mathrm{L}_{1 \ldots \ldots \ldots \ldots} \mathrm{L}_{\mathrm{N}}\right\}, \mathrm{i}=1,2$, $3 \ldots . . . n$, where $\mathrm{n}$ is the number of individuals in the population and $\mathrm{N}$ is the total number of DG sources whose position, L has to be optimized.

3. Calculate the affinity for each set of the candidate solutions. The affinity is based on the fitness function or the objective function. As the objective is to maximize the value of MOTI, affinity can be calculated directly from (7). The antibodies having higher values of the objective function are stored in the memory set and they will have higher affinity.

4. Clonal proliferation is done for antibodies with affinity greater than 0.55 . The antibodies having higher values of the technical index will have higher affinity and hence they will proliferate more. The number of clones produced for an antibody varies between 2 to 5 depending upon its affinity.

5. The maturation process of these clones is achieved through hyper mutation and the rate of it is inversely proportional to the affinity. In this paper both binary and real mutations are done and two mutated individuals are generated for a single clone. Binary mutation is achieved through bit flip mutation. 
6. Tournament selection is used to choose the same fixed number of antibodies as in the initial population. The inferior antibodies in the memory set are replaced with new improved individuals and thus the memory set is updated.

7. The process is repeated until the maximum number of iterations is reached. From the memory set, the solution which gives the maximum value of fitness function is chosen as the optimal location for DG placement.

8. The whole process is repeated for different combinations of discrete DG sizes for a particular value of the total DG capacity.

\section{RESULTS AND DISCUSSION}

The multi objective optimal DG placement problem is solved using AIS in MATLAB environment. The personal computer configuration is Intel(R) core, $2.3 \mathrm{GHz}, 4$ GB RAM. The test system considered is the standard 33 bus radial distribution network given in Figure 1, with 32 branches including 3 laterals. The real and reactive power of the connected loads for this network is $3.72 \mathrm{MW}$ and 2.3 MVAR respectively. The real and reactive power losses for this radial distribution network without DG sources are $210.998 \mathrm{~kW}$ and 143 $\mathrm{kVar}$ respectively. Three different cases are considered wherein the total DG capacity is $1 \mathrm{MW}, 2 \mathrm{MW}$ and 3 MW. For each of these cases, different combinations of three DG sources of predetermined discrete sizes are considered. The DG sources are chosen from a universal set consisting of DGs with capacities ranging from $0.125 \mathrm{MW}$ to $2.25 \mathrm{MW}$.

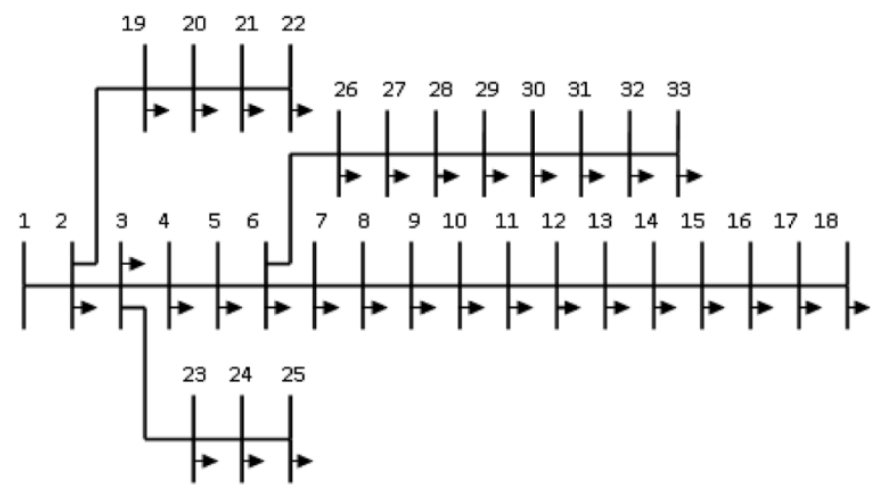

Figure 1. IEEE 33 bus radial distribution network

The optimal DG placement problem is solved using artificial immune system. The maximum number of iterations is set as 100 and the number of individuals in the population is 50. For each case, the optimal solution is obtained after performing 20 trial runs. The four objectives used in the formulation of MOTI are given equal importance by considering the value of each weight as 0.25 . The results obtained are shown in Table 1. The solution obtained from AIS for the combination of DG sizes $375 \mathrm{~kW}, 750 \mathrm{~kW}$ and $1875 \mathrm{~kW}$ (case 2) are at nodes 17, 31 and 3. The real and reactive power loss for this optimal solution is $76.92 \mathrm{~kW}$ and $55.02 \mathrm{kVar}$. In order to understand the significance of optimal siting of DG sources, the same DGs are placed at a random location i.e. at nodes 2, 17 and 33. The load flow analysis performed with DGs at the random location gives increased real and reactive power loss amounting to $178.89 \mathrm{~kW}$ and $138.48 \mathrm{kVar}$ respectively. 
Table 1. Optimal DG locations obtained using AIS

\begin{tabular}{|c|c|c|c|c|c|c|c|c|c|c|}
\hline $\begin{array}{l}\text { Case } \\
\text { No. }\end{array}$ & DG sizes (MW) & $\begin{array}{l}\text { Total } \\
\text { DG } \\
\text { size } \\
(\mathrm{MW})\end{array}$ & $\begin{array}{c}\text { DG } \\
\text { location }\end{array}$ & MOTI & $\begin{array}{l}\text { Real } \\
\text { Power } \\
\text { from } \\
\text { utility } \\
\text { (MW) }\end{array}$ & $\begin{array}{l}\text { Reactive } \\
\text { power } \\
\text { from } \\
\text { utility } \\
\text { (MW) }\end{array}$ & $\begin{array}{l}\text { P loss } \\
\text { (MW) }\end{array}$ & $\begin{array}{l}\text { Q loss } \\
(\mathrm{MW})\end{array}$ & VRI & VSI \\
\hline 1 & $0.75,0.75,1.5$ & & $31,14,3$ & 0.77042 & 0.78862 & 2.35169 & 0.07362 & 0.0517 & 0.8935 & 0.8987 \\
\hline 2 & $0.375,0.75,1.875$ & & $17,31,3$ & 0.74927 & 0.79191 & 2.35501 & 0.07692 & 0.05502 & 0.89382 & 0.85259 \\
\hline 3 & $1.125,1.125,0.75$ & 3 & $3,11,31$ & 0.75611 & 0.79621 & 2.3566 & 0.08122 & 0.0566 & 0.8929 & 0.91236 \\
\hline 4 & $0.375,1.5,1.125$ & & $32,3,11$ & 0.74698 & 0.79609 & 2.35651 & 0.08109 & 0.05652 & 0.90957 & 0.85798 \\
\hline 5 & $0.375,0.375,2.25$ & & $25,16,6$ & 0.73437 & 0.79966 & 2.361 & 0.08467 & 0.06101 & 0.91664 & 0.84871 \\
\hline 6 & $0.75,0.75,0.5$ & & $14,31,25$ & 0.78511 & 1.78138 & 2.34649 & 0.06638 & 0.0465 & 0.88844 & 0.8918 \\
\hline 7 & $0.5,0.5,1$ & & $25,16,30$ & 0.77326 & 1.78466 & 2.34947 & 0.06967 & 0.04948 & 0.87515 & 0.89413 \\
\hline 8 & $0.25,1,0.75$ & 2 & $25,12,31$ & 0.77038 & 1.78847 & 2.35118 & 0.07348 & 0.05118 & 0.89037 & 0.89737 \\
\hline 9 & $0.25,0.5,1.25$ & & $25,32,10$ & 0.75533 & 1.79356 & 2.35452 & 0.08185 & 0.05682 & 0.90216 & 0.87286 \\
\hline 10 & $0.25,0.25,1.5$ & & $31,32,9$ & 0.72781 & 1.80533 & 2.36327 & 0.09034 & 0.06327 & 0.90381 & 0.87811 \\
\hline 11 & $0.375,0.375,0.25$ & & $32,16,30$ & 0.7184 & 2.80292 & 2.36067 & 0.08792 & 0.06067 & 0.89926 & 0.8154 \\
\hline 12 & $0.125,0.25,0.625$ & & $18,16,31$ & 0.71913 & 2.8031 & 2.3608 & 0.0881 & 0.0608 & 0.89931 & 0.82003 \\
\hline 13 & $0.125,0.5,0.375$ & 1 & $18,32,14$ & 0.72053 & 2.80455 & 2.36091 & 0.08955 & 0.06091 & 0.90476 & 0.82784 \\
\hline 14 & $0.25,0.25,0.5$ & & $14,17,31$ & 0.72038 & 2.80462 & 2.36101 & 0.08963 & 0.06101 & 0.90479 & 0.82824 \\
\hline 15 & $0.125,0.125,0.75$ & & $16,18,31$ & 0.70904 & 2.80435 & 2.36268 & 0.08935 & 0.06268 & 0.89333 & 0.80472 \\
\hline
\end{tabular}

Figure 2 shows the variation of real, reactive power loss, VRI and VSI for different cases. From the figure it is clear that if priority is given to losses, then the best solution is case 6 as shown in Table 1 . If improvement in voltage regulation is considered, then the location and size for the DG sources are given by case 5. If prime importance is given for voltage stability, then case 3 gives the best combination of DG sources along with their position in the distribution network. Figure 3 illustrates the improvement in voltage stability due to DG installation for case 3. For the case without DG sources, the minimum value of VSI is 0.6692 , whereas for case 3 it is 0.9244 .

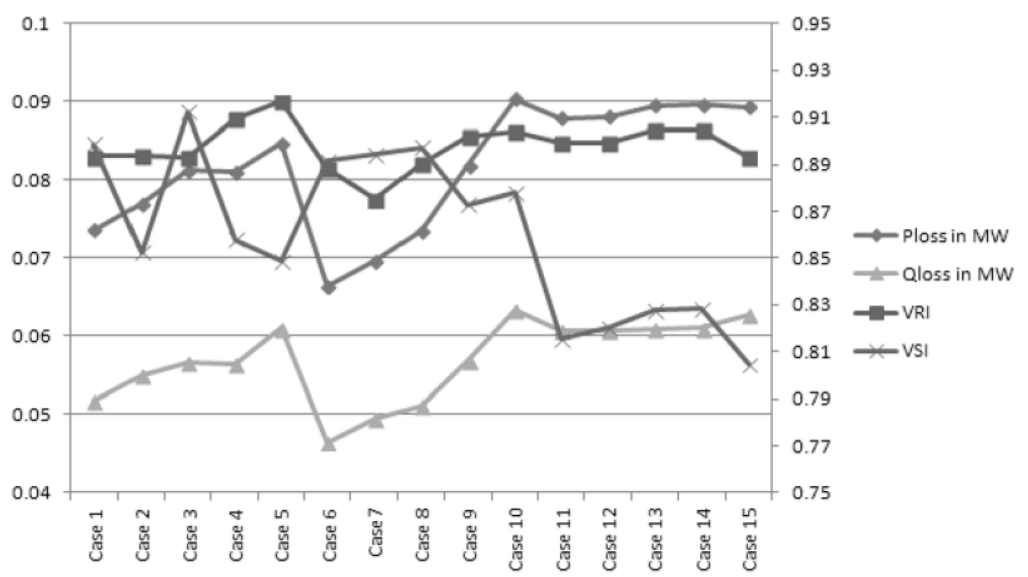

Figure 2. $\mathrm{P}_{\text {loss }}$, $\mathrm{Q}_{\text {loss }}$, VRI and VSI for different cases

The solution which gives the minimum real and reactive power loss may not have the best values for VRI or VSI. The optimal solution is a compromise solution which will never have the worst values for any objective functions and may/may not have the best objective function values. From Table 1, it is found that when all the objectives are considered with equal importance, the optimal solution is obtained for case 6 for a total DG capacity of $2 \mathrm{MW}$. DG sources of capacity $750 \mathrm{~kW}, 750 \mathrm{~kW}$ and $500 \mathrm{~kW}$ are installed at nodes 14 , 
31 and 25 respectively. For this case the real and reactive power loss is $66.383 \mathrm{~kW}$ and $46.495 \mathrm{kVar}$. There is a significant reduction of about $68.53 \%$ for real power loss and $67.48 \%$ for reactive power loss in comparison with the case when DG sources are not installed.

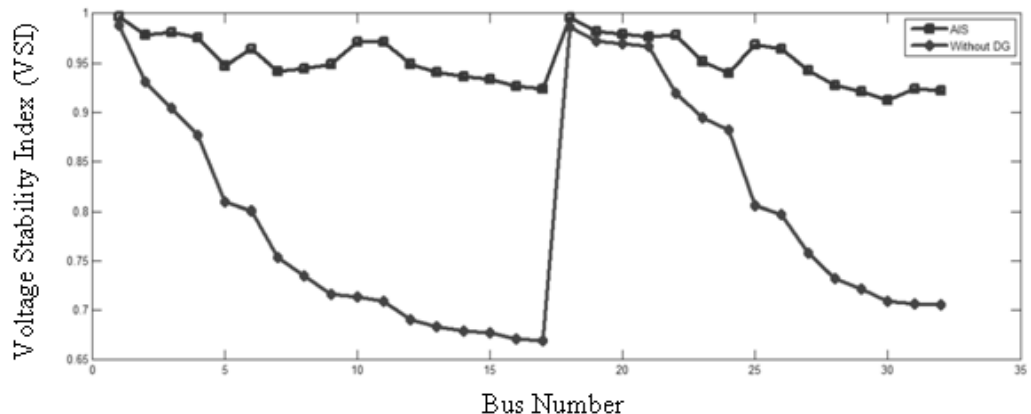

Figure 3. Improvement in voltage stability index

The multiobjective problem is solved using GA and PSO to validate the results of AIS. The same set of initial population generated for AIS is used for PSO and GA. The parameters used for GA and PSO are given in Table 2.

Table 2. Parameters for PSO and GA

\begin{tabular}{cc}
\hline PSO & GA \\
\hline Number of particles $: 50$ & Population size $: 50$ \\
Cognitive parameter, $\mathrm{c}_{1}: 2$ & Crossover rate, $\mathrm{c}_{\mathrm{p}}: 0.6$ \\
Social parameter, $\mathrm{c}_{2}: 2$ & Mutation rate, $\mathrm{m}_{\mathrm{p}}: 0.2$ \\
Constriction parameter, $\mathrm{C}: 0.5$ & \\
Inertia weight, $\mathrm{w}_{\max }, \mathrm{w}_{\min }: 0.9,0.4$ & \\
\hline
\end{tabular}

Figure 4 compares the values of MOTI obtained from the three algorithms. AIS gives comparatively better results than PSO and GA. The optimal solution obtained from PSO is also for case 6 when MOTI is 0.78511. GA maximizes MOTI to 0.76213 for the optimal solution. This is obtained when DGs with capacities $250 \mathrm{~kW}, 1000 \mathrm{~kW}$ and $750 \mathrm{~kW}$ are located at nodes 25,12 and 29 respectively.

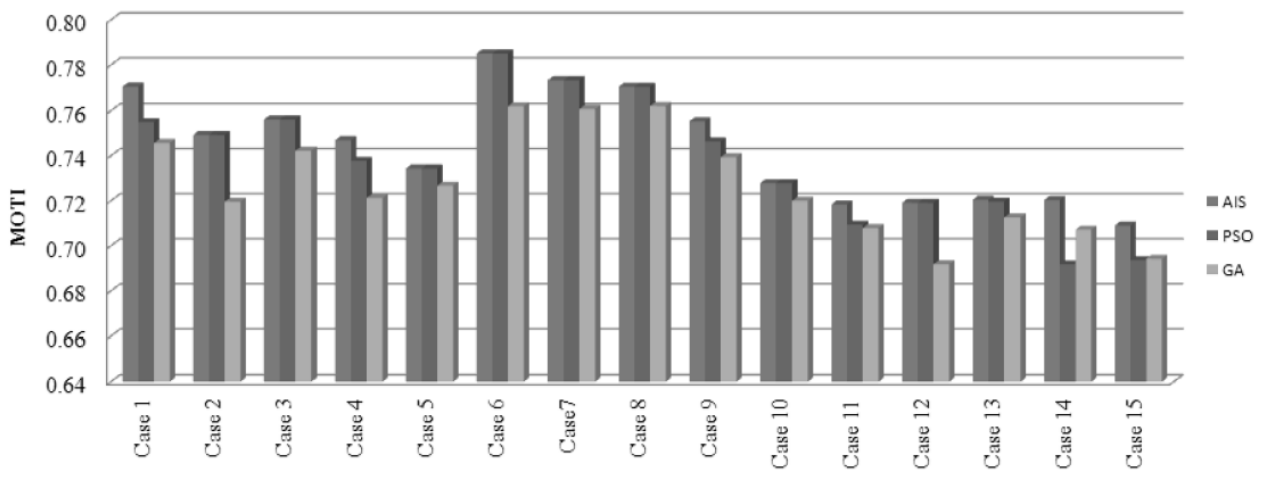

Figure 4. Comparison of MOTI values obtained using AIS, PSO and GA

The values of different indices for 3 different combinations of DG sources obtained from AIS, PSO and GA are given in Table 3. For a total DG capacity of $3 \mathrm{MW}$ with the combination of DGs as $750 \mathrm{~kW}, 750$ $\mathrm{kW}$ and $1500 \mathrm{~kW}$, the three algorithms give different locations. The voltage profile plots for these locations 
are compared in Figure 5. The voltage profile improves when DGs are installed and the best profile is for the solution obtained from AIS.

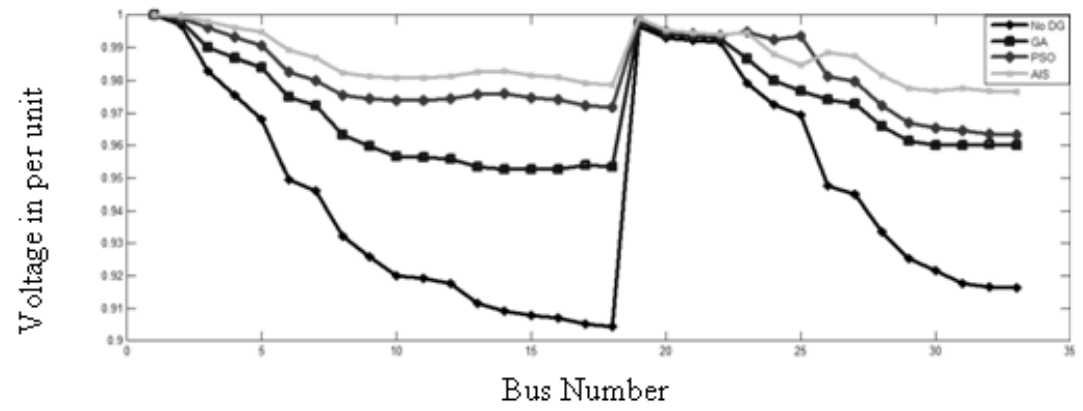

Figure 5. Voltage profile for AIS, PSO and GA solutions

Table 3. Comparison of optimal DG locations obtained using AIS, PSO and GA

\begin{tabular}{|c|c|c|c|c|c|c|c|c|}
\hline $\begin{array}{c}\text { DG } \\
\text { size } \\
(\mathrm{MW})\end{array}$ & $\begin{array}{l}\text { Total DG } \\
\text { size (MW) }\end{array}$ & $\begin{array}{l}\text { Algorithm } \\
\text { used }\end{array}$ & DG location & MOTI & $\mathrm{P}$ loss $(\mathrm{kW})$ & $\mathrm{Q}$ loss (kW) & VRI & VSI \\
\hline 0.75 & \multirow{3}{*}{$3 \mathrm{MW}$} & AIS & $31,14,3$ & 0.77042 & 73.62212 & 51.69907 & 0.89350 & 0.89870 \\
\hline 0.75 & & PSO & $31,14,19$ & 0.75492 & 78.53461 & 54.82914 & 0.89102 & 0.88436 \\
\hline 1.5 & & GA & $10,33,4$ & 0.74571 & 82.34966 & 57.65219 & 0.89301 & 0.88330 \\
\hline 0.25 & \multirow{3}{*}{$2 \mathrm{MW}$} & AIS & $25,32,10$ & 0.75533 & 81.85221 & 56.81886 & 0.90216 & 0.87286 \\
\hline 0.50 & & PSO & $25,16,30$ & 0.74641 & 81.32867 & 57.88740 & 0.86378 & 0.91212 \\
\hline 1.25 & & GA & $23,30,12$ & 0.73940 & 83.66999 & 58.35121 & 0.90185 & 0.86039 \\
\hline 0.125 & \multirow{3}{*}{$1 \mathrm{MW}$} & AIS & $18,32,14$ & 0.72053 & 89.54901 & 60.91182 & 0.90476 & 0.82784 \\
\hline 0.5 & & PSO & $14,32,16$ & 0.71967 & 89.80639 & 61.25903 & 0.90477 & 0.82802 \\
\hline 0.375 & & GA & $31,13,33$ & 0.71261 & 90.88615 & 62.57832 & 0.90461 & 0.81429 \\
\hline
\end{tabular}

Figure 6 shows the convergence characteristics for the three algorithms. AIS converges to the optimal solution in less number of iterations compared to PSO and GA. The time taken per iteration is more for AIS. However, the optimal siting of DG sources is a planning problem and time is not a constraint. Therefore AIS is a good choice to obtain the optimal location for DG sources in a distribution network.

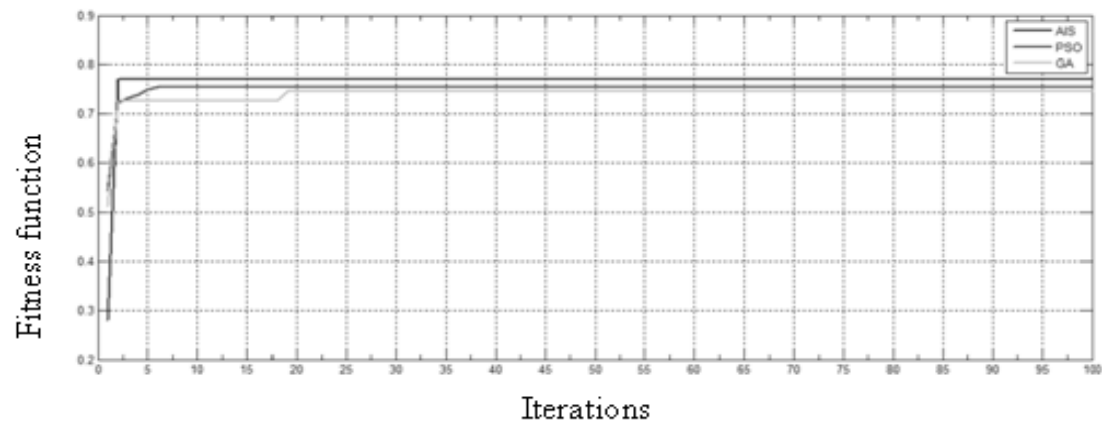

Figure 6. Convergence characteristics for AIS, PSO and GA

\section{CONCLUSION}

In this paper the effectiveness of AIS in attaining the optimal solutions for the DG placement problem is analyzed by comparing it with PSO and GA solutions. The problem is solved by using a multiobjective technical index, termed MOTI. The objective is to minimize the total real and reactive power loss, 
improve the voltage profile, voltage regulation and voltage stability. The problem is solved using clonal selection based AIS algorithm for the installation of multiple DG sources in a distribution network. The sizes of the DG sources are chosen from a universal set consisting of discrete DG capacities. The results prove the suitability of using AIS for the optimal DG placement problem in distribution networks.

\section{REFERENCES}

[1] Ackermann T, et al., "Distributed generation: a definition", Electric power systems research, vol. 57, pp. 195-204, Apr 2001.

[2] W. El-Khattam and M.M.A. Salama, "Distributed generation technologies, definitions and benefits", Electric Power Systems Research, vol.71, pp. 119-128, 2004.

[3] Zhaohong Bie, et al., "Reliability evaluation of active distribution systems including micro grids", IEEE Transactions on Power Systems, vol. 27(4), pp. 2342-2350, 2012.

[4] K. Balamurugan, et al., "Impact of distributed generation on power distribution systems", Energy Procedia, vol.25, pp. 93-100, 2012.

[5] Caisheng Wang and M. Hashem Nehrir, "Analytical approaches for optimal placement of distributed generation sources in power systems", IEEE Transactions on Power Systems, vol. 19(4): pp. 2068-2076, 2004.

[6] M. Ahmadigorji, et al., "Optimal DG sizing in primary distribution feeders using dynamic programming approach", Proceedings of the 11th International Conference on Environment and Electrical Engineering (EEEIC), pp. 371-375, 2012.

[7] Soma Biswas, et al., "Optimum distributed generation placement with voltage sag effect minimization", Energy conversion and Management, vol.53, pp. 163-174, 2012.

[8] Pavlos S. et al., "Optimal distributed generation placement in power distribution networks: Models, methods and future research", IEEE Transactions on Power Systems, vol. 28(3), pp. 3420-3428, 2013.

[9] Fahad S. et al., "Optimal distributed generation allocation and sizing in distribution systems via artificial bee colony algorithm", IEEE Transactions on Power Delivery, vol. 26(4), pp. 2090-2101, 2011.

[10] R. Srinivasa Rao, et al., "Power loss minimization in distribution system using network reconfiguration in the presence of distributed generation," IEEE Transactions on Power Systems, vol. 28 (1), pp. 317-325, 2013.

[11] Mostafa F. et al., "DG Allocation for benefit maximization in Distribution networks", IEEE Transactions on Power Systems, vol. 28(2), pp. 639-649, 2013.

[12] V. Ravikumar Pandi, et al., "Determining optimal location and size of distributed generation resources considering harmonic and protection coordination limits", IEEE Transactions on Power Systems, vol. 28(2): pp. 1245-1254, 2013.

[13] Binayak Banerjee and Syed M. Islam. "Reliability based optimum location of distributed generation", Electrical Power and Energy Systems, vol.33, pp. 1470-1478, 2011.

[14] R.S. Al Abri, et al., "Optimal placement and sizing method to improve the voltage stability margin in a distribution system using distributed generation", IEEE Transactions on Power Systems, vol. 28(1), pp. 326-334, 2013.

[15] Luis F. Ochoa, et al., "Evaluating distributed time varying generation through a multiobjective technical index", IEEE Transactions on Power Delivery, vol. 23(2), pp. 1132-1138, 2008.

[16] Soo-Hyoung Lee and Jung-Wook Park, "Selection of optimal location and size of multiple distributed generations by using Kalman Filter algorithm", IEEE Transactions on Power Systems, vol. 24(3), pp.1393-1400, 2009.

[17] A. Sadighmanesh, et al., "Distributed generation unit and capacitor placement for multi objective optimization", International Journal of Electrical and Computer Engineering, vol. 2(5), pp. 615-620, 2012.

[18] J.J. Jamian, et al., "Implementation of Evolutionary Particle swarm optimization in distributed generation sizing", International Journal of Electrical and Computer Engineering, vol. 2(1), pp. 137-146, 2012.

[19] Komail Nekooei, et al., "An improved multi-objective harmony search for optimal placement of DGs in distribution systems", IEEE Transactions on Smart Grid, vol. 4(1), pp. 557-567, 2013.

[20] Amir Ameli, et al., "A multiobjective particle swarm optimization for sizing and placement of DGs from DG owner's and distribution company's viewpoints", IEEE Transactions on Power Delivery, vol. 29(4), pp. 1831-1840, 2014.

[21] Zhaoyu Wang, et al., "Robust optimization based optimal DG placement in microgrids", IEEE Transactions on Smart Grid, vol. 5(5), pp. 2173-2182, 2014.

[22] M.H. Moradi and M. Abedini, "A combination of genetic algorithm and particle swarm optimization for optimal DG location and sizing in distribution systems", Electric Power and Energy Systems, vol. 34, pp. 66-74, 2012.

[23] Abu Mouti F S and El Hawary M E, "A new and fast power flow solution algorithm for radial distribution feeders including distributed generations", Proceedings of the IEEE International Conference on Systems, Man and Cybernetics, pp. 2668- 2673, 2007.

[24] Leandro N. de Castro and Fernando J. Von Zuben, "Learning and optimization using the clonal selection principle", IEEE Transactions on Evolutionary Computation, vol. 6(3), pp. 239-251, 2002.

[25] John E. Hunt and Denise E. Cooke, "Learning using an artificial immune system", Journal of Network and Computer Applications, vol. 19, pp. 189-212, 1996. 